\title{
A Prospective Study on Laparoscopic Varicocelectomy: Efficacy and Safety
}

\author{
Dr. Deepak Kumar ${ }^{1}$, Dr. Devendra Kumar Shiwach², Dr. Saloni Mehra ${ }^{3}$, \\ Dr. Bharat Veer Manchanda ${ }^{4}$ \\ ${ }^{1}$ Assi. Professor inDept Of Surgery, Subharti Medical College, Meerut \\ ${ }^{2}$ Assi. Professor inDept Of Surgery, Rama Medical College, Hapur \\ ${ }^{3}$ Post Graduate in Dept Of Surgery, SubhartiMedicalCollege, Meerut \\ ${ }^{4}$ Assi. Professor inDept Of Medicine, Subharti Medical College, Meerut
}

\section{Introduction}

Varicocele develops due to incompetent valves in testicular vein. It refers to the abnormal veins in the pampiniform plexus (PP) which are tortuous and dilated. It presents as scrotal asymmetry, scrotal heaviness and rarely with testicular pain. Many a times, adults are unaware of the varicocele. It is usually discovered accidentally during a regular physical examination or during the recruitment for military service. ${ }^{1}$ The incidence of high-grade varicocele is approximately $15 \%$ all over the world and found in one third of the males with infertility ${ }^{2,3}$

Different approaches have been applied for treatment of varicocele, including microscopic open surgery, embolization, and recently, laparoscopy. ${ }^{4,5}$ In 1991, Aaberg and colleagues ${ }^{6}$ introduced laparoscopy as the least-invasive surgical method in the treatment of varicocele.

The outcome of the treatment of varicocele depends on the technique used as well as on the skills of the surgeon performing the procedure. Various randomized controlled trials have compared the efficacy of conventional and the laparoscopic approach ${ }^{7}$ Current study was planned to highlight the efficacy and safety of laparoscopic varicelectomy discussed in terms of postoperative pain, operative time, hospital stay, semen analysis(semenogram) before and after the procedure and complications during and after the procedure .

\section{Materials and Methods}

A prospective observational study was carried out at a tertiary care hospital in Surgical Unit in Meerut, over a period of 2 years. All the patients included in the study were suffering from varicocele based on clinical criteria (scrotal asymmetry, heaviness in scrotum and testicular pain)confirmed by scrotal ultrasound, ages between 15 to 45 years and who had to undergo laparoscopic high ligation of varicocele.

Exclusion criteria; Patients with varicocele secondary to malignancy or venous obstruction, with history of previous lower abdominal surgery and those with ASA grade above II.

After obtaining the approval from the hospital ethical committee, written and informed consent was taken from each patient. The diagnosis of varicocele was made by physical examination with the Valsalva maneuver. Doppler ultrasonography was also performed using the probe placed over the spermatic cord in the subinguinal area. Doppler exam could document retrograde blood flow in the spermatic cord, which confirmed the diagnosis. A pre operative seminogram was also sent for all the patients . A record of operative time, post operative pain,durationof hospital stay and semen analysis at 3 ans 6 months post operatively was made for each patient.

All patients received perioperative intravenous antibiotics, usually ceftriaxone with dose adjusted according to their age. All surgeries were performed under general/ spinalanasesthesia, by consultant surgeons well experienced in the procedures to minimize bias. Laparoscopic high ligation was be done by inserting three ports, testicular vessels were approached transperitoneally and testicular vein was clipped and divided. Wound was closed with absorbable suture materials. Operative time for each case was calculated in minutes by the trainee researcher using a standard stop watch who was personally present in the theater from the time of incision or insertion of ports till last skin stitches. Length of postoperative hospital stay was calculated in terms of days from date of admission to discharge as mentioned in the patients' notes. All the data were recorded on designed proforma. Mean and standard deviation were calculated for all quantitative data (age, operative time, postoperative pain length of hospital stay, sperm count before and after, recurrence, complications if any ). Means of sperm counts before and after was compared using unpaired $t$ test. 


\section{Patients}

\section{Results}

The present study included a total of 50 patients; The age of the patients in laparoscopic high ligation ofvaricocele ranged from 15 to 45 years with a mean age of $27.32 \pm 7.37$ years $30(60 \%)$ varicoceles were on the left side , $12(24 \%)$ were bilateral and $8(12 \%)$ on right side.

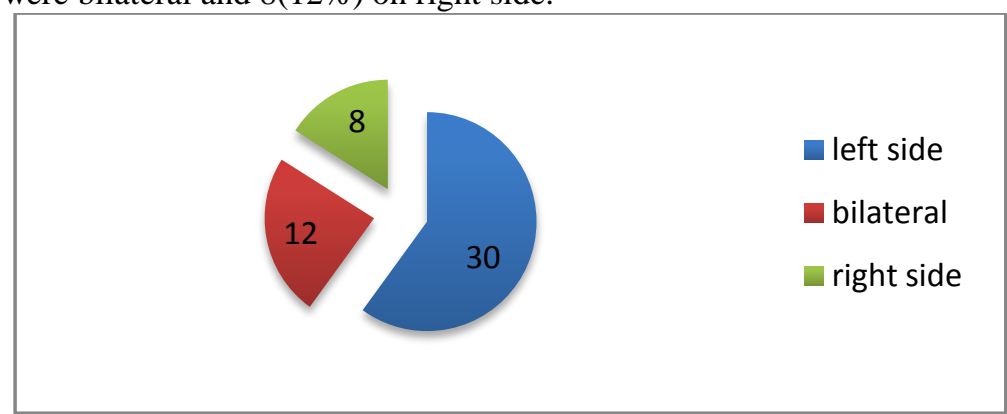

Figure 1: Distribution of patients according to side of varicocel

\section{Operative time}

The operation time was calculated from skin incision to skin closure for laparoscopic high ligation of varicocele. The operative time ranged from $25-60$ minutes. With 30.6 \pm 8.86 minutes for unilateral cases and $45.37 \pm 7.3$ for bilateral case .

Figure 2:mean of operative time for unilateral and bilateral cases .

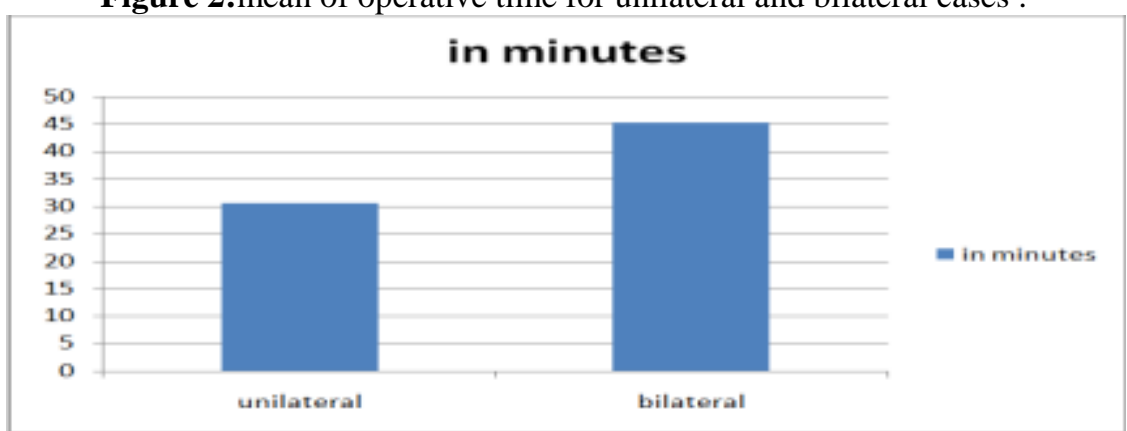

Figure 2

\section{Post operative complications}

Out of 50 patients 5 patients had complications .2\% (1) developed pneumoscrotum, $2 \%$ developed wound site infection, inferior epigastric bleed in $2 \%$ (1) patient and recurrence occurred in $4 \%$ (2)of the patients . Thus 90\% of the patients had good results and only 10\% developed complications .FIGURE 3 : various post operative complications encountered in the study

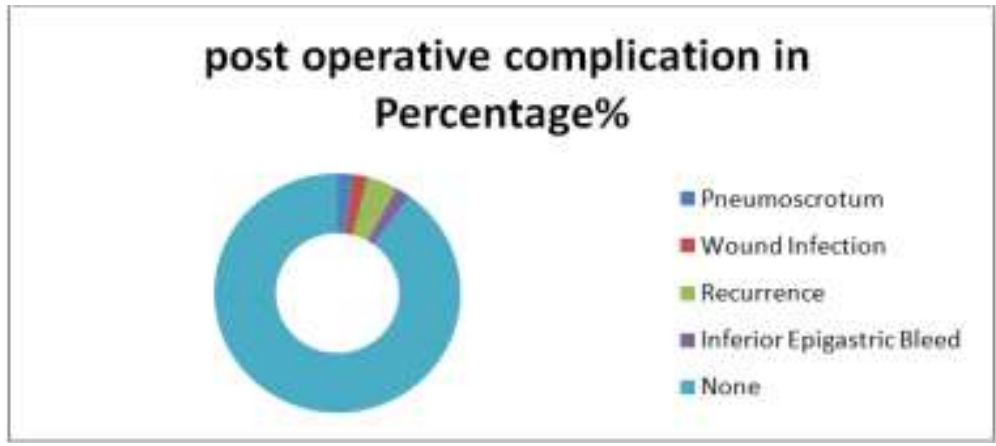

Figure 3

\section{Sperm count}

The semen analysis was done pre operatively, post operatively at 3 months and at 6 months . The pre operative count was $33.2 \pm 20.40$ million $/ \mathrm{ml}$ there was a significant increase in sperm count post operatively in 3 months $46.6 \pm 16.1 \mathrm{million} / \mathrm{ml}$ (p:0.0004) and at 6months $60.22 \pm 20.78 \mathrm{million} / \mathrm{ml}$ (p:0.0001) when compared to pre operative values FIGURE 4: mean of sperm counts pre operatively,post operatively at 3 months and at 6 months . 


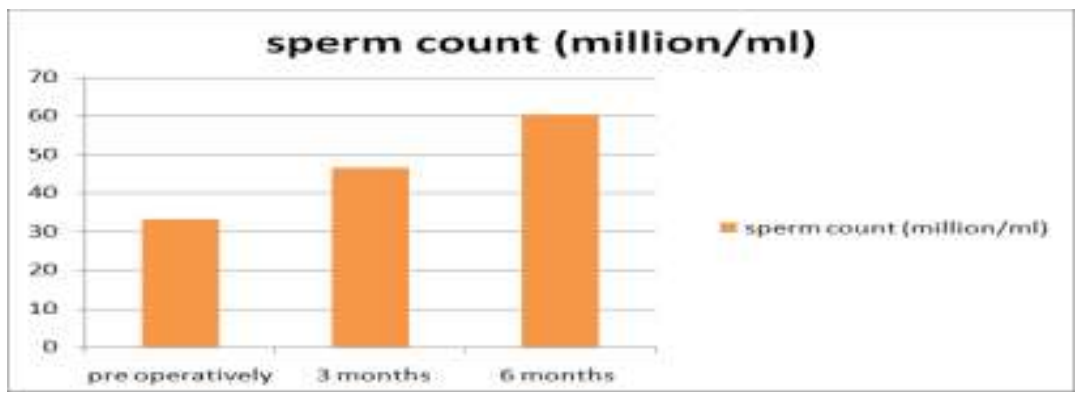

Figure 4

\section{Hospital stay}

The hospital stay was calculated in days from the date of admission to the date of discharge as noted in the patients file ; $5.98 \pm 1.42$ days

\section{Discussion}

There are different surgical methods for varicocele treatment. The first surgical method for varicocele was explained by Celsus in the first century (ipsilateralorchidectomy which consisted of an atrophic testis) ${ }^{8}$ Currently, popular varicocelectomy methods include: the Ivanissevich method (retroperitoneal), Palomo method, subinguinal method (with or without testicular delivery), laparoscopic method, and sclerotherapy (internal spermatic vein embolization). The most effective and least invasive method is yet unknown. We studied the efficacy of laproscopicvaricocelectomy in terms of operative time, post operative complications if any , duration of hospital stay and increase in sperm count after the procedure.

We found that the operation time in patients with laparoscopic procedure was $41.6 \pm 8.86$ minutes in case of unilateral and 100.37 \pm 7.3 minutes in cases of bilateral varicocelecteomy . It was more in case of bilateral than unilateral procedure.Ghanem and colleagues ${ }^{9}$ reported the operative time to be 45 minutes on average for unilateral subinguinal method and 25.6 minutes for the high retroperitoneal method. Watanabe and coworkers ${ }^{10}$ reported an operative time of $111.8 \pm 21.1$ minutes for unilateral high retroperitoneal varicocelectomy and 86.3 \pm 28.4 minutes for unilateral subinguinalvaricocelectomy under LA. The operative time in our group of open surgery with LA was 38 minutes on average. Watanabe and colleagues reported a mean operative time of $109 \pm$ 27 minutes, although their operations were unilateral ${ }^{11}$.Kwon and associates reported a mean of 102 minutes for this parameter. ${ }^{12}$ They did not mention whether this was for unilateral or bilateral varicocelectomy. Ogura and colleagues performed bilateral laparoscopic varicocelectomy on 39 patients with an operative time of 96.6 minutes.

A study done by RahatHasan et al ${ }^{13}$ Operative time for the open high ligation of varicocele with a mean operative time of $38.75 \pm 7.8$ minutes. The operative time ranged from 17 to 60 minutes for the laparoscopic high ligation of varicocele with a mean operative time of $30.48 \pm 10.6$ minutes . The operative time was statistically significantly different between the two groups $(\mathrm{p}=0.000)$.

Varicocele recurrence is a complication of varicocelectomy. Misseri and coworkers reported $3 \%$ recurrence with the Palomo method and 14\% recurrence with the high retroperitoneal method. Al-Kandari and colleagues $^{14}$ studied 120 patients with 147 varicocelectomies in three different methods. The recurrence rate was $2 \%$ (1 patient) with microscopic subinguinalvaricocelectomy and 13\% (7 patients) and 18\% (9 patients) with open inguinal and laparoscopic methods, respectively. This report was statistically significant in favor of microscopic subinguinalvaricocelectomy. Al-Said and coworker ${ }^{15}$ observed the same results (the recurrence rate was $2.6 \%, 11 \%$, and $17 \%$ in microsurgical, open, and laparoscopic groups, respectively).

In our study the recurrence rate was $2 \% ; 4$ patients out of 50 .Other post operative complications reported in our study were pnuemoscrotum in $2 \%$, wound infection in $2 \%$ and inferior epigastric artery bleed in $2 \%$. Jonathan P. Jarow et $\mathrm{al}^{16}$ in a studyon 46 patients reported Complications occurred in 2 patients $(4 \%)$, inferior epigastric vessel bleeding in one, and genitofemoral nerve injury in the other. There was one persistent varicocele $(1 \%)$.Watanabe and colleagues reported $6.1 \%$ recurrence in 33 patients with bilateral laparoscopic varicocelectomy. They mentioned a recurrence rate of $12 \%$ in 50 patients with unilateral varicocelectomy by high retroperitoneal method. ${ }^{17}$ Varicocele recurrence after laparoscopic method was reported to be $8.9 \%$, but stood at $6.7 \%$ when the lymphatic vessels were preserved. ${ }^{18}$

Varicocele has been implicated as a cause in $35-50 \%$ of patients with primary infertility and up to $81 \%$ of men with secondary infertility. ${ }^{19,20}$ The surprisingly high incidence in secondary infertility suggests that varicoceles cause progressive decline in testicular function over time. Although varicocele repair is widely used as a treatment for male infertility, its efficacy has been a subject of intense debate for nearly 50 years. Although the ultimate goal of treating male factor infertility is to increase the pregnancy rate, varicocelectomy also seeks to maximize a couple's fertility potential by improving sperm quality or avoiding a decline in testicular 
function.O'Brien et al. ${ }^{21}$ evaluated the outcomes of two cohorts of infertile men with varicocele who had female partners at least 35 years old $(n=202)$. One group chose to receive microsurgical varicocelectomy, and the other chose observation. Sperm count and total motility significantly increased after varicocele repair $(\mathrm{p}<0.05)$.

Tan et al12 22 conducted a study on 108 varicocelectomies. The operation was performed on a day surgery basis with an average operative time of $61.4 \mathrm{~min}$ (56.6 min for unilateral and $75.8 \mathrm{~min}$ for bilateral high ligation of varicocele). They reported low morbidity, pneumoscrotum in 2 patients and wound infection in the other 2. Sixty-one patients showed improved sperm count and their motility. Hence they concluded that laparoscopic high ligation of varicocele is beneficial and effective that causes least discomfort and offers an early return to the usual life.

The laparoscopic varicocelectomy has been performed by many surgeons on a day-surgery basis, ${ }^{23,24}$ .The mean hospital stay after laparoscopic varicocelectomy in our study was $5.98 \pm 1.42$ days . Iselin CE et $\mathrm{al}^{25}$ reported the mean length of hospital stay ( 0.9 days) and median total recovery time ( 5 days) were remarkably short. The length of hospital stay was not affected by whether the patient had unilateral or bilateral varicocoele.

\section{Conclusion}

We conclude that laparoscopic varicocelectomy is safe, effective and minimally invasive. In addition to its better cosmetic results and advantage in case of bilateral disease, it allows excellent exposure and control of the affected vessels. Furthermore, the shorter hospital stay and the earlier return to normal activities are very important advantages in recommending this technique as an efficient alternative to the open surgical method.

\section{Bibliography}

[1] Cooper CS, Joudi FN, Williams RD. Urology. In: Doherty GM (edi) Current diagnosis and treatment: Surgery. 13th ed. USA: McGraw-Hill Companies, Inc. 2010;902-65.

[2] Çayan S, Shavakhabov S, Kadioglu A. Treatment of palpable varicocele in infertile men: A Meta-analysis to define the best technique. J Androl 2009;30:33-40. 3 Chen C. Varicocele in male factor infertility: role of laparoscopic high ligation of varicocele. Int Surg. 2006;91:90-4.

[3] Hassan JM, Adams MC, Pope JCt, Demarco RT, Brock Jw, 3rd. Hydrocele formation following laparoscopic varicocelectomy. J Urol. 2006;175:1076-9.

[4] Kocvara R, Dvoracek J, Sedlacek J, Dite Z, Novak K. Lymphatic sparing laparoscopic varicocelectomy: a microsurgical repair. J Urol. 2005;173:1751-4.

[5] Misseri R, Gershbein AB, Horowitz M, Glassberg KI. The adolescent varicocele. II: the incidence of hydrocele and delayed recurrent varicocele after varicocelectomy in a long-term follow-up. BJU Int. 2001;87:494-8.

[6] Aaberg RA, Vancaillie TG, Schuesslerww. Laparoscopic varicocele ligation: a new technique. FertilSteril. 1991;56:776-7.

[7] Al-KandariAM, Shabaan H, Ibrahim HM, Elshebiny YH, Shokeir AA. Comparison of outcomes of different high ligation of varicocele techniques: Open Inguinal, Laparoscopic, and Subinguinal Microscopic High ligation of varicocele: A Randomized Clinical Trial. Urology 2007;69:417-20.

[8] Spink MS, Lewis GL. Albucasis on surgery and instruments. Berkeley: University of California Press, 1973. p 438.

[9] Ghanem H, Anis T, El-Nashar A, Shamloul R. Subinguinalmicrovaricocelectomy versus retroperitoneal varicocelectomy: comparative study of complications and surgical outcome. Urology. 2004;64:1005-9.

[10] watanabe M, Nagai A, Kusumi N, Tsuboi H, Nasu Y, Kumon H. Minimal invasiveness and effectivity of subinguinal microscopic varicocelectomy: a comparative study with retroperitoneal high and laparoscopic approaches. Int J Urol. 2005;12:892-8.

[11] Kwon ED, Sandlow JI, Donovan JF. Varix ligation. In: Smith AD, Badlani GH, Bagley DH, editors. Smith's textbook of endourology. 1st ed. St Louis: quality Medical Publishing; 1996. p. 894-903.

[12] Ogura K, Matsuda T, Terachi T, Horii Y, Takeuchi H, Yoshida O. Laparoscopic varicocelectomy: invasiveness and effectiveness compared with conventional open retroperitoneal high ligation. Int J Urol. 1994;1:62-6.

[13] RahatHasan, Asifa Dian, MuhammadHanifAzam Yusuf Hamid Hassan et al. Comparison of the Efficacy of Laparoscopic Versus Open High Ligation for Varicocele 2012.

[14] Al-KandariAM, Shabaan H, Ibrahim HM, Elshebiny YH, Shokeir AA. Comparison of outcomes of different varicocelectomy techniques: open inguinal, laparoscopic, and subinguinal microscopic varicocelectomy: a randomized clinical trial. Urology. 2007;69:417-20.

[15] Al-Said S, Al-Naimi A, Al-Ansari A, et al. Varicocelectomy for male infertility: a comparative study of open, laparoscopic and microsurgical approaches. J Urol. 2008;180:266-70.

[16] Jonathan P. Jarow, M.D. *, Dean G. Assimos, M.D., Donald E. Pittaway, M.D. Effectiveness of laparoscopic varicocelectomy Volume 42, Issue 5, November 1993, Pages 544-547.

[17] Watanabe M, Nagai A, Kusumi N, Tsuboi H, Nasu Y, Kumon H. Minimal invasiveness and effectivity of subinguinal microscopic varicocelectomy: a comparative study with retroperitoneal high and laparoscopic approaches. Int J Urol. 2005;12:892-8.

[18] Kocvara R, Dvoracek J, Sedlacek J, Dite Z, Novak K. Lymphatic sparing laparoscopic varicocelectomy: a microsurgical repair. J Urol. 2005;173:1751-4.

[19] Gorelick JI, Goldstein M. Loss of fertility in men with varicocele. Fertility and sterility. 1993;59:613-6.

[20] Witt MA, Lipshultz LI. Varicocele: a progressive or static lesion? Urology. 1993;42:541-3.

[21] O’Brien JH, Bowles B, Kamal KM, Jarvi K, Zini A. Microsurgical varicocelectomy for infertile couples with advanced female age: natural history in the era of ART. J Androl. 2004;25:939-43.

[22] Tan SM, Ng FC, Ravintharan T, Lim PH, ChngHC.Laparoscopic high ligation of varicocele: technique and results. Br J Urol 1995; 75:523-8.

[23] Fuse H, Okumura A, Sakamoto M, Ohta S, Katayama T. Laparoscopic varicocele ligation. IntUrolNephrol. 1996;28(1):91-97

[24] Winfield H, Donovan J. Laparoscopic varicocelectomy. Sem Urol. 1992;10:152

[25] Iselin CE, Almagbaly U, BorstF , Rohner S, Schmidlin F, Campana A Graber PSafety and efficiency of laparoscopic varicocelectomy in one hundred consecutive cases.1997;58(4):213-7. 